\title{
The first biomanipulation conference: a synthesis
}

\author{
Eddy H. R. R. Lammens, ${ }^{1}$ Ramesh D. Gulati, ${ }^{2}$ Marie-Louise Meijer, ${ }^{3}$ Ellen van Donk ${ }^{4}$
}

'Limnological Institute, Tjeukemeer Laboratory, De Akkers 47, 8536 VD, Oosterzee, The Netherlands;

${ }^{2}$ Limnological Institute, Vijverhof Laboratory, Rijksstraatweg 6, 3631 AC, Nieuwersluis, The Netherlands;

${ }^{3}$ Institute of Inland Water Management and Waste Water Treatment P.O. Box 17, 8200 AA Lelystad;

${ }^{4}$ Agricultural University Wageningen, Department of Nature Conservation, Laboratory of Aquatic Ecology.

P.O. Box 8080, 6700 DD Wageningen, The Netherlands

Key words: size-efficiency hypothesis, phytoplankton : zooplankton interactions, planktivores, benthivores, piscivores, indirect effects, stable states, trophic state

\begin{abstract}
At the First Biomanipulation Conference held in Amsterdam (8-11 August 1989), studies presented considered mainly trophic interactions in lakes, enclosures and laboratory systems. Studies on the interactions between phytoplankton and zooplankton emphasized the edibility of the phytoplankton in relation to the zooplankton size structure and the trophic state. Most lake experiments involved $50-100 \%$ reduction in fish standing stock or alternatively heavy stocking with piscivorous fish. The most dramatic effects of biomanipulation were found in shallow, eutrophic lakes which exhibited radical changes in ecosystem structure because of changes in light climate and consequently, luxuriant development of macrophytes. There was still much controversy about the top-down effects in relation to trophic state, especially those concerning the role of fish and zooplankton in the development and succession of phytoplankton. Many experiments showed indirect effects within the food web, emphasizing the importance of feedbacks and the complexity of the food web rather than the simplicity of the food chain. The stabilizing effects of refugia for zooplankton and fish on the ecosystem were stressed. Shallow lakes responded generally more rapidly to biomanipulation and this was most successfully accomplished when TP concentration was $<50 \mu \mathrm{gl}^{-1}$, even though in a few cases at 10-20 fold higher TP concentrations (mostly $\mathrm{PO}_{4}-\mathrm{P}$ lakes) the results achieved could be maintained for two or more summers. For a guaranteed success of the measures an almost complete removal of fish appeared to be indispensible; moreover in many cases removal of benthivorous fish appeared to be even more important than that of planktivorous fish.
\end{abstract}

\section{Introduction}

Shapiro (1982) originally defined biomanipulation as 'the deliberate exploitation of the interactions between the components of the aquatic ecosystem in order to reduce the algal biomass'. Thinking about manipulating the food web for management purposes started in the early sixties with the works of Hrbáček (1961) and Brooks \& Dodson (1965). They emphasized the role of planktivorous fish in structuring the zooplankton and phytoplankton communities and Brooks \& Dodson (1965) formulated the size-efficiency hypothesis on the phytoplankton-zooplankton interaction. According to this hypothesis the large-sized cladocerans are more efficient feeders 


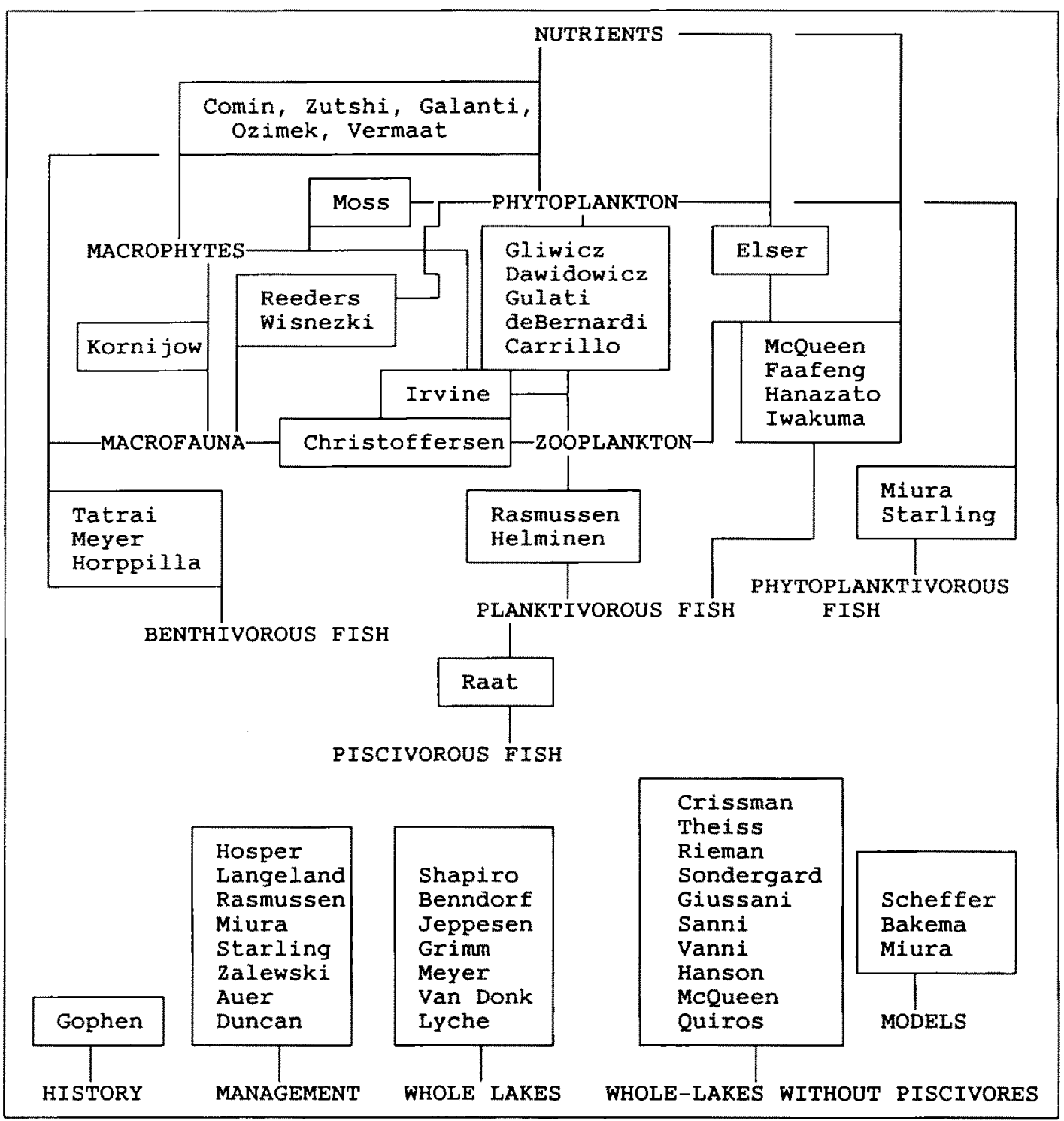

Fig. 1. The components of the food web and their interactions studied by the Conference participants (restricting to the name of first author in multiple author contributions). For references only cited in this figure, but not in the text, see Gulati et al. (1990).

on phytoplankton and the small-sized species have only a chance to become abundant in the presence of high densities of planktivorous fish. By selective predation of fish, the large-bodied zooplankton is replaced by small-sized zooplankton which cannot reduce and maintain the phytoplankton biomass to consistently low levels. Thus, the hypothesis states the importance of grazing pressure of the herbivore zooplankton community and predation on these herbivores by planktivorous fish as the two strong food chain components which regulate the phytoplankton biomass as well as succession. However, the edibility of the phytoplankton changes in relation to trophic state and in eutrophic conditions a very high percentage of the phytoplankton is inedible for even the largest cladocerans. In that case the hypothesis is often rejected and a hypothesis with more nuances is called for to incorporate indirect effects. 
(A), Faafeng et al. (A), Theiss et al. (A) and Gulati (A)), but only if the phytoplankton was dominated by edible species and the zooplankton was composed of large-sized daphnids. In most case studies presented, green algae were dominant in the presence of large-sized daphnids, although the P-levels were very high. Benndorf (A), Faafeng et al. (A), Hanson \& Butler (A) and Vanni et al. (A) reported situations in which the concentration of phytoplankton remained high even though large cladocerans were present. In these studies the phytoplankton was composed predominantly of inedible species, including cyanobacteria.

\section{Indirect effects}

Interesting indirect effects following biomanipulation were reported by Benndorf (A). After several years of low fish predation, mysids had the opportunity to develop and suppress, in their turn, the zooplankton community. He also observed the composition of the phytoplankton community to change because of high grazing pressure by large cladocerans. When planktivores were less abundant and large zooplankton dominated, percentage of inedible forms in the phytoplankton community increased, with virtually no change in the chlorophyll level. Hanazato et al. (A) and Tatrai et al. (A) found indirect effects between fish and rotifers: the densities of copepods were reduced by fish predation, which relieved the predation pressure on the rotifers. The decrease in relative abundance of rotifers in biomanipulated Dutch lakes (Gulati, A) compared with that in non-biomanipulated, eutrophic lakes points to a similar indirect effect. Working with phytoplanktivorous silver carp and large-mouth carp Miura (A) noted an interesting indirect effect. A very high density of silver carp suppressed Microcystis and thus stimulated small green algae which in their turn led to an increased zooplankton development. Large-mouth carp exploited this development and exhibited a better growth than in the presence of Microcystis. The papers of Horppila \& Kairesalo (A), Tatrai et al. (A), Lyche et al. (A) and Meyer et al. (A) demonstrated that benthi- vorous fishes, such as carp, bream and roach have indirect effects on the phytoplankton development because they influence turbity and nutrient dynamics by foraging in the bottom and bringing nutrients back into the pelagic zone.

Indirect effects were also reported to have been mediated by abiotic factors. In particular, the increased availability of light after severe fish reduction promoted the development of macrophytes in shallow ponds and lakes (Ozimek et al., Vermaat et al. (A), Moss (A), Meyer et al. (A), Van Donk et al. (A), Sanni \& Waervagen (A) and Hanson \& Butler (A)). This created a whole new infrastructure and a completely different food web. A more diverse macrofauna community developed (Kornijow, A) and refugia for zooplankton (Moss, A; Irvine, A) and young pike (Grimm \& Backx, A) developed. Moreover, the macrophytes and phytoplankton appeared to compete for nitrogen (Ozimek et al. (A)) and Van Donk et al. (A) found that $\mu$-algae were more successful in these $\mathrm{N}$-limited conditions than macro-algae, thus providing favourable food conditions for the cladocerans.

\section{Ecosystem stability}

A serious problem in the application of biomanipulation is the stability of the ecosystem. Reducing fish stocks is usually only a temporary solution since the fish stock will increase again by recruitment and by growth. Therefore, the system is very likely to return soon to the situation prior to biomanipulation, unless a new stable state can be reached. Regarding this Shapiro (A) made an important contribution in suggesting ways in which fish and zooplankton may be made to coexist by way of creating refugia. In deep lakes, refugia for zooplankton can be available in colder, but less oxygenated, deeper layers in which zooplankton can thrive but fish cannot. In shallow lakes, on the other hand, vegetation is important in this respect (Moss (A), Irvine et al. (A)). According to Moss (A), a strong perturbation is required before lakes with high nutrient concentrations can switch from a stable state dominated 
In this Conference several studies showed that the interaction between zooplankton and phytoplankton is much more complex than stated in the size-efficiency hypothesis, and that the benthivorous fish were sometimes even more important than planktivorous fish, particularly in shallow lakes. Moreover, it appears necessary to distinguish between shallow and deep lakes, since the shallow lakes have a greater potential to develop macrophytes and thus regulate nutrient dynamics, differently from phytoplankton dominated systems. In this synthesis we summarize the presentations by focussing on three main points in biomanipulations studies: edibility of phytoplankton, indirect effects and the stability of the ecosystem after the biomanipulation measures. Then we discuss these results in a more general ecosystem framework and evaluate how crucial the role of zooplankton is. In the last section we give the present state of the art of how to use biomanipulation as tool for water management.

\section{Edibility of phytoplankton}

One of the very important aspects in biomanipulation is the zooplankton-phytoplankton interactions. The probability that phytoplankton will be controlled (limited) by zooplankton not only depends on the absence or low standing stock of planktivorous fish, but also to the quality and quantity of phytoplankton. Gliwicz $(A)^{*}$ and Dawidowicz $(A)$ reformulated the size-efficiency hypothesis to incorporate the effect of filamentous cyanobacteria on feeding efficiency. At high densities of these cyanobacteria smaller-bodied daphnids have a competitive advantage over large-bodied ones because filaments interfere with food filtering of the large daphnids and increase their maintenance metabolism more than in small cladocerans. Therefore, even in the absence of planktivorous fish, large cladocerans will not develop if high concentrations of filamentous cyanobacteria are present. Bernardi (A) reviewed the problems related to the edibility of

* (A) refers to papers presented at this Conference. cyanobacteria and concluded that apart from mechanical interference with filtering, toxic effects of cyanobacteria on the cladocerans may also play an important role.

The papers of Van Donk et al. (A), Rieman et al. (A), Faafeng et al. (A), Tatrai et al. (A), Iwakuma et al. (A), Hanazato et al. (A) and Crisman \& Beaver (A) showed that in absence of planktivorous fish, or its strongly-reduced densities, zooplankton did not inevitably develop into large-sized communities both in enclosure- and whole-lake experiments. This was dependent on quality and quantity of the food or the total absence of daphnids; stocking with Daphnia was found to be a successful technique for the establishment of populations in enclosures or small ponds (Faafeng et al. (A), Theiss et al. (A)), but chlorophyll reductions did not necessarily occur following Daphnia introduction and were dependent on the trophic state (Elser et al. (A)).

According to Lyche et al. (A) the primary effect of fish reduction is the reduction of the internal $\mathrm{P}$-load, because fish is the intermediate agent converting food organisms into nutrients. An increasing $\mathbf{N} / \mathbf{P}$ ratio would result, favouring the green algae. As a consequence, grazing by Daphnia will be more successful. However, Van Donk et al. (A), Benndorf (A), Meyer et al. (A), Vanni et al. (A), Hanson \& Butler (A) and Rieman et al. (A) could not confirm this result. Their studies showed that TP-concentrations did not decrease after fish reduction, but sometimes even increased. There is still much controversy about how fish interfere in the switch from green algae to cyanobacteria and vice versa; it is likely that interplay of abiotic factors (nutrients, light and temperature) and biotic factors (zooplankton and phytoplankton) confound the effects produced. Many indirect effects make it difficult to distinguish among the effects produced especially if they were caused by organisms which are either not monitored or neglected (rotifers and ciliates, for instance).

Several papers reported strong interactions between zooplankton and phytoplankton at high TP-concentrations (Van Donk et al. (A), Meyer et al. (A), Sanni \& Wearvagen (A), Jeppesen et al. 
by 'algal soup' to the other, dominated by macrophytes. Reductions of fish stocks, can cause a turbid shallow lake, without vegetation, to become transparent despite the continuing high nutrient loads (Van Donk et al. (A), Meyer et al. (A), Jeppesen et al. (A), Sondergaard et al. (A), Sanni \& Waervagen (A)) because the development of macrophytes will stabilize the ecosystem for the reasons noted earlier. Scheffer (A) attempted to provide a theoretical basis for it and Grimm \& Backx (A) demonstrated the role of pike and the importance of vegetation to pike. Jeppesen (A), Moss (A), Scheffer (A) and Grimm \& Backx (A) emphasized the effects of nutrient concentration and suggested that switching to the 'algal soup' is easier at TP $>200 \mu \mathrm{g} \mathrm{l}^{-1}$, but there was still little evidence for that. When $\mathrm{N}$-levels are very low $\mu$-algae are stimulated and create favourable conditions for zooplankton grazers. Removing macrophytes is the opposite perturbation which can bring the system in the phytoplankton dominated state, because this increases the impact of wind and activity of benthivorous fish on sediment resuspension (Meijer et al.) and reduces transparency so as to prevent macrophytes to develop (Vermaat et al. (A)).

\section{Biomanipulation and ecosystem research}

In 1960 Hairston et al. (1960) developed an ecosystem model in which 'productivity' and 'trophic levels' were the key words. This model was modified by Oksanen et al. (1981) who suggested that productivity determined the number of trophic levels in an ecosystem and that biomass and production in a given trophic level were determined by the higher trophic levels. Such characteristic effects were called 'cascading' effects (Carpenter et al., 1985). Persson et al. (1988) used this model to integrate bottom-up and top-down effects. As mentioned, such models are limited in their application because of their two main drawbacks (Kerfoot \& DeAngelis, 1989): "first, they are food-chain models rather than food-web models and hence fail to account for the several indirect effects; and second, these models may fail to in- corporate resource-quality responses by the consumers, e.g. edibility and availability of the primary producer for the primary consumers, the herbivore zooplankton".

When considering trophic levels, usually the trophic chain from top to bottom: piscivoresplanktivores-zooplankton-phytoplankton-nutrients is described with its cascading effects within the chain. An essential question is how these trophic levels are defined. To be precise, not only the planktivores form prey for the piscivores, but also benthivores do and, therefore, should be included in the same trophic level as planktivores. Consequently, both zooplankton and benthos should be considered as a trophic level. However, within the zooplankton level similar discrepancies can be found and are difficult to resolve because some forms, especially some copepods may exploit food resources both at primary consumer and primary producer levels, and are, therefore, difficult to categorize; likewise some invertebrate predators may feed both on herbivore and predatory zooplankton and are difficult to classify. So the observed cascading effects give only a birds eye view of interplay and feed backs actually operating in an ecosystem. According to McQueen's (1986) model the interactions in the food chain gradually, weaken downwards in the chain but this can only be seen when just a small part of the food web is considered. For example in shallow, eutrophic Dutch lakes, which have virtually no macro-vegetation, it is, as regards fish, difficult to determine a planktivorous and a piscivorous fish. All the fish species are sizestructured and switch regularly from planktivory to benthivory. Moreover, the piscivores, do not restrict their feeding to only planktivorous fish. Although this cascading-effect theory appears attractive and may be appealing, it generally does not adequately explain the effects of biomanipulation measures.

\section{Zooplankton, the key factor}

In most studies, zooplankton particularly the large-bodied zooplankton species, Daphnia 
hyalina, D. galeata, D. pulicaria and D. magna are the most important, potential causal factor in suppressing the phytoplankton abundance. The effects of zooplankton are generally dramatic once the seston food levels decrease to lie below 2-3 $\mathrm{mg} \mathrm{DW}^{-1}$ or if biomass of herbivore zooplankton, dominated by large-bodied daphnids reaches roughly half as high levels as their food resource (Gulati (A)). On areal basis between 2 and $3 \mathrm{~g} \mathrm{DW} \mathrm{m}^{-2}$ appears sufficient to keep the lakes in a clear water phase (Lampert, 1988). Although the importance of mussel filtration and of macrophytes in competing with algae for nutrients are recognized, they are considered as minor effects if the lake is turbid and without vegetation, but they may be more important when the lake is clear and overgrown. Also important may be the relationship between the effects of zooplankton and the trophic state of the lake. McQueen et al. $(1986,1989)$ are among the first to suggest that the top-down effect of zooplankton on phytoplankton might be related to trophic state, because the edibility of the phytoplankton is related to trophic state as well. Many papers presented show some evidence for this hypothesis (Benndorf (A), Jeppesen et al. (A), Vanni et al. (A), Elser et al. (A), Faafeng et al. (A), Moss (A), Scheffer (A), Hosper \& Jagtman (A)). If the edibility of the phytoplankton is low, the topdown effect is absent; for example, in Tjeukemeer Lammens (1988) reported coincidence of high densities of both Daphnia hyalina and Oscillatoria agardhii.

Because of the importance of zooplankton, planktivorous fish have received more attention than benthivorous fish, although the latter may be predominant in total fish community, especially in shallow lakes. Besides, effect of benthivorous fish is likely to be important because nutrients accumulating at the lake bottom, including faeces of fish and benthic organisms will be brought back into the water column by the fish by resuspension of the bottom sediments (Meyer et al. (A), Horppilla \& Kairesalo (A), Lyche et al. (A), Tatrai et al. (A), Hanazato et al. (A)). This can, however, also be established by wind action (Gons \& Rijkeboer, 1990), particulary in large lakes where waves can develop. Probably the combination of wind and benthivorous feeding has a larger impact than the seperate effects because only little wind is needed to keep already disturbed sediments in suspension.

Because of the importance of the zooplankton the pelagic zone received more attention than the benthic zone. In deep lakes the relationships between the pelagic zone and non-pelagic zones have been neglected, but this symposium went a long way to reaffirm that in shallow lakes pelagic and litteral zones are more relative concepts since depth alone does not limit the growth of macrophytes, but transparency and exposure to wind may be crucial. The switch from a macrophytes dominance (littoral) to that by phytoplankton (pelagial), as mentioned earlier, is probably influenced by benthivorous fish directly and indirectly: directly by adversely affecting the light climate for macrophytes and indirectly by reducing nutrient limitation for algae (Meyer et al. (A)). The fish community and macrofauna also change with macrophyte development (Lammens, 1989; Grimm \& Backx (A), Kornijow (A)) and, therefore, in shallow lakes the community changes as a whole. Though our knowledge of deeper lakes in this respect is much more limited, it is most likely that they essentially differ in the aspects mentioned from the shallow lakes.

\section{Management}

The Biomanipulation Conference had one of its aims, to develop a review of the state of art of studies to date and their application potential to serve as tool in solving problems relating to lake management. Some of the studies presented were unintentional applications of biomanipulation to water quality management. Zalewski et al. (A) reported the effect of water level variations in a Polish reservoir on the recruitment of young fish and its cascading effects on the phytoplankton. The possibility of water level regulation makes the reservoir more open to management, although one would expect the feedback effects to become discernible after a few years. In this regard 
Benndorf (A) observed that in Bautzen reservoir (DDR) mysids appeared to feed on zooplankton and inedible forms became dominant in phytoplankton. Duncan (A) reported that in Thames valley reservoirs in London, which receive highly eutrophic water from the river Thames, the fish biomass is relatively low due to a lack of suitable spawning places, this allows the development of a high zooplankton biomass. Consequently, in early summer apparently the grazing pressure is high and biomass of phytoplankton is lower than expected from nutrient concentrations. But in lake summer the phytoplankton composition shifts to inedible species so that zooplankton is ineffective in regulating phytoplankton. Such a negative feedback effect will reduce the possibility of biomanipulation as tool for water management unless other measures are taken. These measures should be aimed at reducing the rate of nutrient loading to increase the chances for dominance of edible algae. Several studies (McQueen et al. (A), Jeppesen et al. (A), Elser et al. (A), Vanni et al. (A), Benndorf (A) and Hosper \& Jagtman (A)) emphasized this, but the large variation between lakes does not give much evidence for this. At total P-concentrations between 50 and $200 \mu \mathrm{g} \mathrm{I}^{-1}$ (Jeppesen et al., A ; Moss, A) chances of success will be generally variable, but above this level the chances of success will much less than below this level. It is, however, important to consider the $\mathrm{N}$-levels as well, especially at higher $\mathrm{P}_{-} \mathrm{PO}_{4}$-levels when chances of $\mathrm{N}$-limitation increase. In such a situation $\mu$-algae are likely to be favoured (Van Donk et al. A). Because of their high turnoverrate, these algae may thus contribute to sustenance of filter-feeding zooplankton (Gulati, A).

Raat (A) and Helminen (A) advocated the use of bioenergetics models to calculate food consumption of piscivorous and planktivorous fish and thus determine the desired density of these fishes to keep the predation pressure on large zooplankton low. Large daphnids are undoubtedly important and, therefore, a goal of biomanipulation must be a stable coexistence of fish and large daphnids. Shapiro (A) emphasized the importance of refugia for zooplankton and mentioned temperature and oxygen as examples in stratefied lakes. Some Daphnia species can tolerate larger temperature differences and lower oxygen levels than fish and can descend to deeper layers to escape predation during the day by vertical migration and ascend to feed in the surface layers during the night. In shallow lakes refugia for zooplankton are assured by macrophytes which reduce accessibility to planktivorous fish and can create oxygen conditions which are not favourable to these fish. In open, shallow water or in deep unstratified layers, large zooplankton can survive only in the absence of fish. The latter situation is hard to maintain and after a while, feedbacks will occur by the appearance of invertebrate predators on zooplankton (e.g. mysids). Benndorf (A) advocated the presence of a moderate fish density to prevent such feedbacks. The combination of refugia for zooplankton, strongly reduced P-loads or N-limitation if P-loads continue to be high (Van Donk et al. A) will increase the chances to create a stable ecosystem.

Gophen (A) emphasized that biomanipulation of very eutrophic lakes can also be achieved by stocking with phytoplanktivorous fish, particulary in subtropic and tropic areas, where according to Crissman (A) no large daphnids seem to develop. Miura (A) presented an example of balanced mixtures of phytoplanktivorous silver carp and zooplanktivorous bighead carp to replace Microcystis by more acceptable green algae. Starling (A) recommended silver carp stocking because this fish used the production efficiently and caused side effects less than other fish species. Rasmussen (A) reported successful stocking of Coregonus lavaretus in Danish hypertrophic lakes which are commercially much more valuable than common cyprinids.

An important outcome of this first Conference on Biomanipulation is that results obtained for deep and shallow lakes differ, especially with regard to higher potential for growth of macrophytes in shallow lakes than in the deep ones. The impact of benthivorous fish and wind on turbity and nutrient regeneration is much higher than in deep lakes, whereas stabilizing effects of macrophytes are unimportant in deep lakes. The recipes for reducing eutrophication by biomanipulating 
are only partly developed and there is still a long way to go, we need long-term experiments in a variety of lakes, before we possibly have tailormade remedial measures for different lakes. It goes without saying that both the aquatic ecologist and water manager have to act in concert to decide if biomanipulation is needed as a complementary measure or as a step when nutrient reduction has failed to produce the desired restoratory effects.

\section{References}

Andersson, G., 1984. The role of fish in lake ccosystems and in limnology. In; Interaksjoner mellom trofiske nivaer i ferskvann, ed B. Bosheim \& M. Nicholls, 189-197. Nordisk limnologsymposium, 1984, Oslo.

Benndorf, J., 1990. Conditions for effective biomanipulation: conclusions derived from whole-lake experiments in Europe. Hydrobiologia 200/201: 84-203.

Bernardi, R. de \& G. Giussani, 1990. Are blue-green algae a suitable food for zooplankton? An overview. Hydrobiologia 200/201: 29-41.

Brooks, J. L. \& S. I. Dodson, 1965. Predation, body size and composition of plankton. Science 150: 28-35.

Carpenter, S. R. (ed.), 1988. Complex interactions in lake communities. Springer Verlag. 283 pp. Carpenter, S. R., J. F. Kitchell \& J. R. Hodgson, 1985. Cascading trophic interactions and lake productivity. BioScience 35 : 634-639.

Crisman, T. L. \& J. R. Beaver, 1990. Applicability of planktonic biomanipulation for managing eutrophication in the subtropics. Hydrobiologia 200/201: 177-186.

Dawidowicz, P., 1990. Effectiveness of phytoplankton control by large-bodied and small-bodied zooplankton. Hydrobiologia 200/201: 43-47.

Duncan, A., 1990. A review: limnological management and biomanipulation in the London reservoirs. Hydrobiologia 200/201: 541-548.

Elser, J. J., H. J. Carney \& C. R. Goldman, 1990. The zooplankton-phytoplankton interface in lakes of contrasting trophic status: an experimental comparison. Hydrobiologia 200/201: 69-82.

Faafeng, B. A., D. O. Hessen, A. Brabrand \& J. P. Nilssen, 1990. Biomanipulation and food-web dynamics - the importance of seasonal stability. Hydrobiologia 200/201: 119-128.

Gliwicz, M., 1990. Why do cladocerans fail to control algal blooms? Hydrobiologia 200/201: 83-97.

Gons, H. \& M. Rijkeboer, 1990. Algal growth and loss rates in Lake Loosdrecht: first evaluation of the roles of light and wind on a basis of steady state kinetics. Hydrobiologia 191: $129-138$.
Gophen, M., 1990. Biomanipulation: retrospective and future development. Hydrobiologia 200/201: 1-11.

Grimm, M. P. \& J. G. M. Backx, 1990. The restoration of shallow eutrophic lakes, and the role of northern pike, aquatic vegetation and nutrient concentration. Hydrobiologia 200/201: 557-566.

Gulati, R. D., 1990. Structural and grazing responses of zooplankton community to biomanipulation of some Dutch water bodies. Hydrobiologia 200/201: 99-118.

Gulati, R. D., E. H. R. R. Lammens, M.-L. Meijer \& E. van Donk (eds), 1990. Biomanipulation, tool for water management (First International Conference, 8-11 August, 1989). Developments in Hydrobiology. Kluwer Academic Publishers, Dordrecht.

Hairston, N. G., F. E. Smith \& L. B. Slobodkin, 1960. Community structure, population control and competition. Am. Nat. 94: 421-425.

Hanazato, T., T. Iwakuma \& H. Hayashi, 1990. Impact of whitefish on an enclosure ecosystem in a shallow eutrophic lake: selective feeding of fish and predation effects on the zooplankton communities. Hydrobiologia 200/201: 129-140.

Hanson, M. A. \& M. G. Butler, 1990. Early responses of plankton and turbidity to biomanipulation in a shallow prairie lake. Hydrobiologia 200/201: 317-327.

Heiminen, H., J. Sarvala \& A. Hirvonen, 1990. Growth and food consumption of vendace (Coregorus albula (L.) in lake Pyhäjärvi, SW Finland: a bioenergetics modeling analysis. Hydrobiologia 200/201: 511-522.

Horppila, J. \& T. Kairesalo, 1990. A fading recovery: the role of roach (Rutilus rutilus L.) in maintaining high phytoplankton productivity and biomass in Lake Vesijärvi, southern Finland. Hydrobiologia 200/201: 153-165.

Hosper, S. H. \& E. Jagtman, 1990. Biomanipulation additional to nutrient control for restoration of shallow lakes in The Netherlands. Hydrobiologia 200/201: 523-524.

Hrbáček, J., M. Dvorakova, V. Korinek \& L. Prochazkova, 1961. Demonstration of the effect of the fish stock on the species composition and the intensity of metabolism of the whole plankton association. Verh. int. Ver. Limnol. 14: 192-195.

Irvine, K., B. Moss \& J. Stansfield, 1990. The potential of artificial refugia for maintaining a community of largebodied cladocera against fish predation in a shallow eutrophic lake. Hydrobiologia 200/201: 379-389.

Iwakuma, T., H. Hayashi, I. Yasuda, T. Hanazato \& K. Takada, 1990. Impact of whitefish on an enclosure ecosystem in a shallow eutrophic lake: changes in nutrient concentrations, phytoplankton and zoobenthos. Hydrobiologia 200/201: 141-152.

Jeppesen, E., J. P. Jensen, P. Kristensen, M. Søndergaard, E. Mortensen, O. Sortkjær \& K. Olrik, 1990. Fish manipulation as a lake restoration tool in shallow, eutrophic, temperate lakes 2: thresholds, long-term stability and conclusions. Hydrobiologia 200/201: 219-227.

Jeppesen, E., M. Søndergaard, E. Mortensen, P. Kristensen, 
B. Riemann, H. J. Jensen, J. P. Müller, O. Sortkjær, J. P. Jensen, K. Christoffersen, S. Bosselmann \& E. Dall, 1990. Fish manipulation as a lake restoration tool in shallow, eutrophic temperare lakes 1: cross-analysis of three Danish case-studies. Hydrobiologia 200/201: 205-218.

Kerfoot, W. C. \& A. Sih (ed.), 1987. Predation: direct and indirect impacts on aquatic communities. University Press of New England. $386 \mathrm{pp}$.

Kerfoot, W. \& D. L. DeAngelis, 1989. Scale-dependent dynamics: zooplankton and the stability of freshwater food webs. Trends in Ecology and Evolution 4: 167-171.

Kornijow, R., R. D. Gulati \& E. van Donk, 1990. Hydrophyte-macroinvertebrate interactions in $Z$ wemlust, a lake undergoing biomanipulation. Hydrobiologia 200/201: 467-474.

Lammens, E. H. R. R., 1988. Trophic interactions in the hypertrophic lake Tjeukemeer: top-down and bottom-up effects in relation to the hydrology, predation and bioturbation during the period 1974-1985. Limnologica (Berlin) 19 : 81-85.

Lammens, E. H. R. R., 1989. Causes and consequences of the success of bream in Dutch eutrophic lakes. Hydrobiol. Bull. 23: 11-19.

Lyche, A., B. A. Faafeng \& Ả. Brabrand, 1990. Predictability and possible mechanisms of plankton response to reduction of planktivorous fish. Hydrobiologia 200/201: 251-261.

McQueen, D. J., J. R. Post \& E. L. Mills, 1986. Trophic relationships in freshwater pelagic ecosystems. Can. J. Fish. aquat. Sci. 43: 1571-1581.

McQueen, D. J., M. R. S. Johannes \& J. R. Post, 1989. Bottom-up and top-down impacts on freshwater pelagic community structure. Ecol. Monogr. 59: 289-309.

McQueen, D. J., M. R. S. Johannes, N. R. Lafontaine, A. S. Young, E. Longbotham \& D. R. S. Lean, 1990. Effect of planktivore abundance on chlorophyll- $a$ and Secchi depth. Hydrobiologia 200/201: 337-341.

Meijer, M.-L., M.W. de Haan, A.W. Breukelaar \& H. Buiteveld, 1990. Is reduction of benthivorous fish an important cause of high transparency following biomanipulation in shallow lakes? Hydrobiologia 200/201: 303-315.

Miura, T., 1990. The effects of planktivorous fishes on the plankton community in an eutrophic lake. Hydrobiologia 200/201: 567-579.

Moss, B., 1990. Engineering and biological approaches to the restoration from eutrophication of shallow lakes in which aquatic plant communities are important components. Hydrobiologia 200/201: 367-377.

Oksanen, L., S. D. Fretwell, J. Arruda \& P. Niemela, 1981. Exploitation ecosystems in gradients of primary productivity. Am. Nat. 118: 240-261.

Ozimek, T., R. D. Gulati \& E. van Donk, 1990. Can macrophytes be useful in biomanipulation of lakes? The Lake Zwemlust example. Hydrobiologia 200/201: 399-407.

Persson, L., G. Andersson, S. F. Hamrin \& L. Johansson,
1988. Predator regulation and primary production along the productivity gradient of temperate lake ecosystems. In: S. R. Carpenter (ed), Complex interactions in lake communities. Springer-Verlag, New York: 45-68.

Porter, K. G., 1977. The plant-animal interface in freshwater ecosystems. Am. Sci. 65: 159-170.

Raat, A. J. P., 1990. Production, consumption and prey availability of northern pike (Esox lucius), pikeperch (Stizostedion lucioperca) and European catfish (Silurus glanis): a bioenergetics approach. Hydrobiologia 200/201: 497-509.

Rasmussen, K., 1990. Some positive and negative effects of stocking whitefish on the ecosystem redevelopment of Hjarbæk fjord, Denmark. Hydrobiologia 200/201: 593-602.

Reeders, H. H. \& A. Bij de Vaate, 1990. Zebra mussels (Dreissena polymorpha): a new perspective for water quality management. Hydrobiologia 200/201: 437-450.

Riemann, B., K. Christoffersen, H. J. Jensen, J. P. Müller, C. Lindegaard \& S. Bosselmann, 1990. Ecological consequences of a manual reduction of roach and bream in a eutrophic temperate lake. Hydrobiologia 200/201: 241-250.

Sanni, S. \& S. B. Waervågen, 1990. Oligotrophication as a result of planktivorous fish removal with rotenone in the small, eutrophic, Lake Mosvatn, Norway. Hydrobiologia 200/201: 263-274.

Scheffer, M., 1990. Multiplicity of stable states in freshwater systems. Hydrobiologia 200/201: 475-486.

Shapiro, J., B. Forsberg, V. Lamarra, G. Lindmark, M. Lynch, B. Smeltzer \& G. Zoto, 1982. Experiments and experiences in biomanipulation studies of biological ways to reduce algal abundance and eliminate blue-greens. EPA-600/3-82-096. Corvalis Environmental Research Laboratory, U.S. Environmental Protection Agency, Corvalis, Oregon.

Shapiro, J., 1990. Biomanipulation: the next phase-making it stable. Hydrobiologia 200/201: 13-27.

Søndergaard, M., E. Jeppesen, E. Mortensen, E. Dall, P. Kristensen \& O. Sortkjær, 1990. Phytoplankton biomass reduction after planktivorous fish reduction in a shallow, eutrophic lake: a combined effect of reduced internal P-loading and increased zooplankton grazing. Hydrobiologia 200/201: 229-240.

Starling, F. L. R. M. \& A. J. A. Rocha, 1990. Experimental study of the impacts of planktivorous fishes on plankton community and eutrophication of a tropical Brazilian reservoir. Hydrobiologia 200/201: 581-591.

Tatrai, I., G. Tóth, L. Ponyi, J. Zlinskaky \& V. Istvánovics, 1990. Bottom-up effects of bream (Abramis brama L.) in Lake Balaton. Hydrobiologia 200/201: 167-176.

Theiss, J., K. Zielinski \& H. Lang, 1990, Biomanipulation by introduction of herbivorous zooplankton. A helpful shock for eutrophic lakes? Hydrobiologia 200/201: 59-68.

Van Donk, E., M.P. Grimm, R. D. Gulati \& J. P. G. Klein-Breteler, 1990. Whole-lake food-web manipulation 